\title{
Understanding Health Exposures and Vulnerabilities of Women Workers and their Work Changes
}

\author{
Sukanya Mohanty \\ Ph.d Research Scholar, \\ Centre for Social Medicine \& Community Health, \\ Jawaharlal Nehru University
}

Doi: 10.2478/ajis-2018-0010

\begin{abstract}
The paper looks at employment shifts of women construction and domestic workers and explores whether social and economic factors as well as processes are adequate in explaining and understanding the reason of health for work changes. It uses the gender model of social determinants of health to explore how women workers differed on the basis of exposures. This paper uses the case studies data of 33 respondents who were purposively selected on the basis of reasons cited for work change from a larger survey sample. The study was conducted in slums of Cuttack city, in Odisha state of India from June 2014 to February 2015.It was found that women's health exposures were psychosocial and physical in form, wherein both affected each other. Exposures occurred on a daily as well as episode basis. Structural and community level factors of women's work, living and diet conditions, access of health care and family support were found crucial for her health besides the individual level wherein her predisposition and age factor mattered. Class, gender, age, family support and state support were the reasons of differential experiences of exposures to conditions and vulnerabilities that affected women's health. Gendered social determinants of health (SDH) along with life course approach helps understand accumulation of health risks over time through the exposures and vulnerabilities as lack of time for recovery, lack of compensation during work loss and challenges of accessing health care invariably led to accumulation of health issues.
\end{abstract}

Keywords: exposures, vulnerabilities, social determinants of health

\section{Introduction}

The social determinants of health (SDH) approach located the health inequalities in systemic inequities and inequalities of social groups. Studies have recognized the causal determination of social inequalities in health by socio- economic environment or position rather than just biological factors. The Population Council (2007:840-1) cites the Whitehall study findings about differences in health of population according to their socio-economic position. Mortality rates were higher for those who had lower position in occupational hierarchy such as clerks in comparison to executives, professionals and administrators. According to Graham (2004), fundamental to structural causes of health is socio-economic position. Hankivisky (2012) adopts intersectionality to study health as she finds the complexity of health could be understood by questioning the 'stability' of categories and remaining open to various dimensions. Krieger, Alegria, Almeida-filho, Barbosa, Barreto, Beckfield et.al (2010) find gaps in the approach of social determinants of health as it overlooks the political factors and addresses only social and economic environment as responsible factors of health thereby questioning de-politicised focus on social environment. They assert that societies reproduce hierarchical relations, labour relations, inequities in the broader economic and political 
context to impact health and health inequities. Graham (2004) has criticized health policy documents for speaking of factors and processes at the same time. The environment or position would be different than the process associated. Labonte \& Schrecker (2007: 18) cite Diderichsen, Evans \& Whitehead's framework on globalization and SDH that identified processes or "four main mechanisms - social stratification, differential exposure, differential susceptibility and differential health consequences- that play a role in generating health inequities in the larger social and political context, globalization and differences in health systems". Marmot, Friel, Bell, Houwelling \& Taylor (2008) acknowledge the pervasiveness of gender inequities in all societies. Sen \& Ostlin (2007) provided a framework for gender as a SDH, wherein they identified three important stages, the structural causes of SDH, the intermediary factors of SDH and the consequences of health. While social stratification, notably gender and structural processes consisted of the structural causes, the intermediary factors of SDH were discriminatory values, norms, practices and behaviours, differential exposures to diseases, disabilities and injuries, biases in health systems and health researches. They have considered political factors of health along with social stratification. The complex of intermediary factors affected each other. Sen \& Ostlin (2007: 44) cite Soucie's finding that people suffering from diseases such as haemophilia when from marginalised social backgrounds were more vulnerable with worse complications and survival rates than the privileged. Sen \& Ostlin (2007: 42-3) cite Ostlin's observation that even where men die earlier than women, most studies on morbidity from both high and low income countries show higher rates of illness among women. Women lose more DALYs (disability adjusted life years) when it comes to HIV, reproductive infections and cancers, eye sight, migraine, mental health, muscle and bone strength, ageing, nutrition and burns. Krieger (2003) brought forth the case of earlier age at onset of perimenopause among women experiencing greater cumulative economic deprivation over the life course. This health condition of women even though is sex-linked, is accelerated by life-long poverty, underlining the gender relations, work conditions and living conditions. Doyal (1995) says in poorest parts of the world, it is the physical strains of household labour that become more visible as women's workload intensifies against the backdrop of social upheavel, economic recession and ecological deterioration. McGibbon \& McPherson (2010) found women combined paid employment and unpaid domestic work to maintain themselves and their households which had profound implications for their health and well-being. Doyal (2000) makes an important observation by acknowledging that illnesses can be traced back to women's daily lives. Sen \& Ostlin (2007: 32) cite studies such as by George and lyer which have found that gender discrimination and biases affect access to health services. Such discrimination could arise from gendered norms of sexuality, reproduction and female occupation. Doyal (2000) observes that there exists a complex interaction between social, psychological and biological dimensions of health.

\subsection{Research Question}

The first research question of this paper is whether the social determinants of health framework or socio-economic factors and processes are adequate in explaining and understanding the phenomenon of health of women construction and domestic workers and their work changes. If gaps are there, how they could be explained? The second question is what were the similarities and differences between women construction and domestic workers who witnessed employment shifts due to health factors?

\subsection{Perspective}

Structural causes, intermediary processes and consequences of health issues in the gender SDH model by Sen \& Ostlin (2007) along with intersectionality (Hancock 2007) have been used while looking at health issues and work changes of women workers. Hankivisky (2012: 1714) emphasizes the significance of analysis considering intersectionality and cites Springer et.al who considered 'various aspects of social status' such as gender, race, socio-economic status and how these induced health conditions in 'complex and multiplicative ways'. 


\section{Methods}

Mixed methods of survey and case study were used for the study. A 50 percent sample of households in the selected slums was chosen by systematic random sampling of alternate households. Whenever a household had joint family and two women were residing in, the preference was based on whether she was working and earning at the time of survey or in the past. If both the women were found earning then, the elder amongst them was chosen. Case studies were selected based on previous work and reasons cited for work change by the respondent. Method of case study was used to know her health and other associated conditions of work change. Case study interviews were conducted in at least three different sittings with prior appointment from each respondent, each sitting ranged between 30-60 minutes.

\subsection{Location}

Cuttack city in Odisha state of India was the location of the study. Twelve slums were purposively selected for this study based on information about occupation of women residents. The study covered five slums of Pattapol from ward number 14, three slums of Ranihat from ward number 27, one slum each from Ranihat and Chattra Bazaar from ward number 34 and two slums of Odiya Bazaar from ward number 15.

\subsection{Sampling}

The survey found 198 women out of a total of 494 had undergone work changes, i.e. approximately 40 percent of the survey sample had either witnessed employment shift or change in their working status. Of these 198, 27 percent stated that health was the reason for shifting or quitting from work. 33 case studies were purposively sampled from the 198 women. Of the 33, 12 and 7 were previously construction workers and domestic workers, respectively. Rest 14 had worked as both construction and domestic workers at different points of time. 27 and 6 women were purposively chosen as they had cited reasons of health and reasons of child care or work demands at home, respectively. Women underwent work changes in different phases of their life. 4 of them when they were around 60 years of age, 13 of them when they were around 50 years of age, 9 of them underwent such change when they were in their 40s, and 7 women had work changes when they were either in their 20 s or 30 s. 16 women of the 33 had undergone employment shifts and the rest 17 had quit working. This paper uses case studies data ${ }^{1}$.

\section{Analysis Results}

\subsection{Work conditions and health exposures}

It was found that none of the domestic workers had injuries at work sites. 4 women construction workers aged 45 years or above had met with injury. Three of them narrated how they had slippery feet, felt dizzy and weak on the day when they had a fall and injury. They did not take notice of their health issues till that incident. Bhudei fell down at construction work site, when she was about 45 years of age, experienced knee issues of swelling and fever. She did not go for health checkups then and was mentally disturbed with her life. She had witnessed death of her babies, asthmatic husband, and young son within 3-4 years, after 12 years and 18 years of marriage, respectively. She was struggling to discipline her adopted young son at home front at the time of accident.

Pratima fell down at construction work site post her recovery from pneumonia when she was nearing her 60s. Post injury they were either pushed out of work or were hesitant to work for the fear of recurrence of a fall and possible injury. They did not have the strength to do such heavy

\footnotetext{
${ }^{1}$ Pseudo names and not real names have been used to depict case studies for reasons of anonymity and confidentiality.
} 
work as before. In the fourth case, there was a little swelling in her back 15 years ago, which she thought was the result of injury while head loading brick or gravel. She started experiencing impeding health effects after 10-15 years when the swelling increased in its size. She shifted from construction to sweeper work. Injury was found associated with unsafe work conditions of construction work, age and pre-existing physical or mental health conditions. Self-reported construction work conditions were climbing stairs, uneven surface at work site, head load of sand, bricks, cement, gravel and excess heat in summers. The act of climbing stairs with headload was shared as difficult with age. Basanti and Radha said that they quit construction work in their mid40 s as they could not climb stairs with age and knee issues. Their younger counterparts were preferred at work place. Mid-40s was found as a deciding point for such women construction workers' career since health issues could be hampering work chances.

Women construction workers even suffered injuries at their place of secondary work. They combined work for insecurity of construction work and need for extra earnings. Kumari had a vehicle run over her on the road where she was a head load worker of decorative lights for a marriage procession at night. Kantamma had a fall from an inclined surface of a temple while fetching a plant pot where she was working as a helper for a marriage feast. Both did not receive any support from the employer for extensive medication and health checkups, diagnostic tests and surgical procedure required. Their financial condition did not permit them to do so either. Their employer only helped in immediate hospitalization in an emergency ward and observation for a few hours. Post discharge from the ward, they were left on their own. Post injury Kumari could not walk again and Kantamma could not do construction work. International Labour Organisation (ILO) 102 complying member countries are required to enforce the provisions for medical care in such situations ${ }^{2}$. Their secondary work conditions of night hours, work on the road or hills and their state of prolonged engagement in paid work heightened the risk of injury, even if it helped them earn extra. There was no provision for compensation for the months or years of loss of work due to injury.

Self-reported work conditions by domestic workers were bending and half-sitting posture while sweeping and mopping, contact with water while mopping and washing clothes/utensils with bare hands. At times, they washed floors by carrying buckets of water or carried buckets of cleaned utensils/clothes from one floor to another or from an open space to inside of the house. Manikamma, an erstwhile construction and domestic worker had frequent cold related health issues before quitting domestic work. According to her, this was for her 'water' associated work. Kalavati experienced severe asthma within a year of quitting domestic work. She attributes this to the pent up cold inside her body that had accumulated over years of working in water, walking in water logged roads during rains, eating gruel rice and sleeping on cold floor at night. Both experienced persistent cold when they had just reached their 40s given their predisposition. When domestic workers underwent constant cold, it was their work conditions of regular contact with water which interacted with their living conditions such as sleeping on damp floor and not bed, bathing in cold water throughout the year, be it rains or the winter and walking in water logged roads during rains. Other health issues among domestic workers were hand ache, knee ache, and backache for their work load. They found walking to employer's house twice a day strenuous as they aged. Women domestic workers did not have time to go for secondary work as the work days in a month were less flexible. The employer could cut salary for the leave taken or ask to leave in case of any altercation without compensation.

\subsection{Dimensions of stress}

While the worry of getting regular work and uncertainty of work location was expressed by women construction workers, the dissatisfaction with salary was conveyed by women domestic workers

${ }^{2}$ ILO 102 refers to Article 10, Social Security (Minimum Standards) Convention, 1952 (No.102) Convention concerning minimum standards of social security (entry into force: 27 April 1955) Adoption: Geneva, 35th ILC session (28 Jun 1952). 
when they made statements such as 'worked for a monthly salary of Rs.500 for 10 years' or 'employer increased monthly salary to only Rs.800 or Rs.1000'. Helplessness in such job situations was expressed by women workers. According to WHO (2008: 72), "poor work quality may affect mental health almost as much as loss of work."

Women workers were exposed to some amount of mental stress on a daily basis when they managed paid and unpaid work together. Women construction workers started from home around 7.30 or 8 in the morning. Their work got over around or after 6.30 in evening in summers and by 5.30 in winters. Rarely their work site would be nearer home which implied commuting cost, time and its strain. They cooked early in the morning and packed their lunches to work place. They either cooked once again late in the evening or had left over food for dinner. Women domestic workers cooked lunch in between their two work shifts, but it also meant walking twice a day to and from their work place. They worked in one to three employers' houses and managed time accordingly. They showed sense of relief when they reduced the number of houses they were employed in. Domestic chores at home such as cooking, washing, cleaning, keeping water, buying grocery and vegetables were usually done by respondents. In some cases, they had other family members to help them. In such cases, daughters/daughter- in-law helped in the chores. This arrangement witnessed changes with marriage of daughter or paid work of daughter-in-law.

Care burden at home exposed women to intense work load and mental agony and thereafter, illness. Mani attributed her illness to mental turmoil she experienced during her husband's illness. She stayed away from work to care for her paralytic husband day and night for more than one and half years. In her words, she had become 'kala katha' or a piece of burnt black wood during this phase of physical and mental strain. Moving her hands during work resulted in friction with swelled tumour area near her breasts. She had to stop her construction and paper mill work.

For some death in family, brought forth a gloomy mental state that lasted for a year or more and affected their paid work. They experienced low mood, inactivity, confinement to home or less social interaction post death in their family. They left work for mental trauma experienced, yet they did not access any health care. They were fortunate to have financial support from their children during this low phase. Mamina lost her husband to fever even before he could be taken to the hospital. Sadamma, a widow lost two of her sons when they were around 30 years of age. Her eldest son died of jaundice and middle son died suddenly of unknown illness. She quit working after the death of her eldest son. Mamina was compelled to rejoin work after two years of her husband's death as her sons no longer financially supported her. After these two years of break, she did not have the strength to do construction work as before. So, she shifted to domestic work.

Bhudei lost her baby in womb as she ate little and went out for work every day without break. Her babies died within few months or a year of birth when she went out for construction work leaving the baby at home with her ailing husband. She provided for her family and never had enough to eat and feed her baby. She deeply experienced the mental pain when she lost her only surviving young son at 17 years of age to unknown health issue. Every such death was a psychosocial exposure for respondents which had emerged from their class, gender and age intersectionality wherein family support created the differential experiences.

Heavy bleeding during delivery and menopause symptoms of continuous bleeding were found responsible for distress, fatigue and weakness which affected women's work. Heavy debt did not permit Anu, an anaemic construction worker to take rest and pushed her to resume work soon after delivery. Chances of engaging in additional work of helper in marriage functions and earning some money was hindered by menopause bleeding and weakness for Radha. Hypertension cases were seen when the respondent was reaching her 50 s with mental worries such as unfulfilled expectations from her grown up sons or other illness as found for Amma, Mamina, and Budhi. An exception, Kamala in her 40s had high blood pressure triggered by a huge family debt.

\subsection{Lack of food despite earnings}

Even when their situation was financially better than before, women construction and domestic workers regularly experienced hunger as was found in cases of Radha and Asha. Both were around 50 years of age, had working husbands and grown up son/daughter who financially 
contributed to family regularly. Asking about what you had for breakfast today was answered back by both these respondents in somewhat similar terse manner: "what breakfast", "what will we eat?" "gruel rice". The use of 'we' implied financial conditions of the family and the 'breakfast' meal always carried a question mark in most of the households. It was accepted as a way of life.

When it came to drinking or having breakfast at the market, men in the households had their say. Radha's husband used to spend money on his drinking every day before he suffered from jaundice, was bed-ridden and was diagnosed with diabetes. For last five years, he has not been drinking. He was forced to quit drinking for health reasons. This saved Radha of the additional expenses, but she suffered the additional medical expenses and debt. She could not herself do much to control her eldest son's drinking with his group of friends from the slum. Instead, she got him married and sent the couple off to a different state, Andhra Pradesh. Gender and class conditions crisscrossed when of the little earnings of INR 100-200 per day, a woman's husband or son spent INR 50-100 every day. Even on days when the men did not get work they continued spending that money on alcohol by taking the money from the respondent's earnings. Manikamma, Sanju and Kalavati went through this experience. They handled their alcoholic husband or son, struggled with food budget of the family on a daily basis and bore the brunt of emotional scars from regular quarrels in the family. Besides psycho-social stress, alcoholism was a cause of deprived diet conditions and potential debt for women. Out of 33, 28 respondents had witnessed regular drinking of their husbands at some point of time. Of these, 3 had said their husbands took money for drinking, but made sure she and her children got at least two meals every day.

Women construction worker such as Sanju shared the impact of long work schedules on their health via diet schedules. She combined construction work and rag picking work every month. Since, construction work hours were long and fixed, she had lunch at work site. On days of rag picking work, she did not feel like eating rice as she worked day long to collect bottles and cans from piles of litter and filth. She lifted these from filth with her bare hands and did not feel like eating rice with the same hands when work was not over. She preferred eating some snack food which was less expensive than lunch. Ragpicking work was even longer than construction work. She continued picking up rags till she had her sacks full which she could sell for INR 300-400. Sanju viewed her irregular diet timings, long work schedules, and skipping of breakfast meal as the direct cause of her ulcer and its recurrence after 10-12 years. Women domestic workers even if they ignored their breakfast meal at home, received tea and other food items at their employer's place in the morning and sometimes in the afternoon. 4-8 hours of work every day spread over two work shifts with a time interval of 3-4 hours was common. Since their work was in two shifts, they came home and had lunch.

Women's diet conditions was characterized by inadequate and absent meals on a daily basis for prolonged years with events like widowhood, desertion, illness and loss of or shift in work which compounded the deprivation. Women such as Basanti, Bayamma and Ganga who were suddenly widowed without paid work and had young children to care for, prioritized their meals. Gender and class based norms at individual and family level interacted to influence women's diet. Evidence for diet of older women shows that at structural level certain Government schemes such as subsidised ration supply scheme and pension scheme could make a difference. Bhudei, a widow in her 60s could not walk normally and experienced difficulty in getting up from the floor without steroid medication. She slept on floor. She was better off than Pedalamma, a widow in her 60s who had almost lost her vision in one eye and stayed in an under construction site with her alcoholic son. Both worked as construction workers previously. Bhudei had the benefit of the Public Distribution System (PDS) based supply of 35 kilogrammes (kgs) of rice and 4 litres of kerosene. She got a widow pension of INR 300 every month, which she used for drinking tea at a cost of INR 5 every day. She did not have any children staying with her, but she managed with this as she received her cooked meals from her nephew or niece on a daily basis. In return, she gave her supply of rice and kerosene to them. She pawned and sold whatever little gold she had to manage her medication costs. Pedalamma had her son staying in, but he was alcoholic and could not afford house rent or adequate meals. He managed to buy only one lunch meal and a cup of tea for her every day. She did not have the benefit of PDS or widow pension scheme. She spent most of her awake time hungry and did not have a stove to cook in her makeshift home. She could not visit a doctor for her 
eye checkup. Both lost work due to health reasons, one for knee issues and the other for poor vision almost ten years ago. Over time their health issue had escalated into full disability in a situation of loss of earnings, deprived diet, difficult living conditions and challenges of accessing health care.

\subsection{Water and sanitation}

When hand pump was the source of water supply as in two slums from ward number 34 , during times of illness women could not exert force to pump out water. Women asked help from others for getting water for drinking, bathing and washing then or used the water canal. The two slums had pay and use toilets. Each visit cost them between INR 1-3. In one slum, these toilets were used by the residents for defecation. The residents in second slum did not use toilets for reasons of cost. Instead, they used the ground near water canal for defecation. Both the cases of brain malaria and filaria were found in the slum with open defecation. Urination in some corner of the house or ground next to house was a common practice during evenings in both the slums. Women did so to avoid expenses or going to the canal for safety reasons. Kumari was disabled from leg, and every day she dragged her lower part of the body on floor for almost 15-20 meters for attending to nature call near the water canal. After defecation, she preferred to take bath in the water canal as she would be clean immediately and need not ask anyone to pump out water for bathing. In her slum, women took bath in open near hand pump. The water canal was usually dirty with no or reduced flow of water in summers and winters. At home, she received help from her husband mostly for getting water for cooking and drinking. Appiamma who was disabled for her knee issue and could not stand straight for more than five minutes stayed in a different slum in ward number 15. She had a common toilet 4 meters away from her room. She was helped by some neighbor or family member to go to the toilet. Her surroundings were much cleaner than Kumari and even if, she dragged her body or sat on floor it was not littered. In slums of ward 14, 15 and 27, common toilets were either constructed by the Government or land owner free of cost. These toilets were shared by 4-15 families of the neighbourhood. Women could access water from a common tap source point. They carried water from the tap in containers to their homes at a distance of 4-10 meters for drinking and cooking on a daily basis. Graham (2004: 111) says, "even though there is evidence of unequal distribution of 'living standards' and 'health behaviours', there are no models that capture it. The case studies reveal that living conditions exposures were interweaved with other exposures, particularly of health care as they determined illness and recovery.

\subsection{Challenges of accessing medical care}

For a few, allopathic medicine was a source of discomfort and they preferred to stay away from it. Ishwaramma took homeopathic medicine for her acidity, blood pressure and diabetes. With allopathic medicine she developed nausea and loose motion. For Mamina, approaching a doctor for her hand fracture in the hospital was difficult. She was apprehensive of the X-ray, costs and even talking to the doctor. She decided to go for 'kalupadasheka' or heat therapy than regular plastering. This worked for her hand fracture. She felt comfortable going to the traditional heat therapy centre, even if it was at a greater distance from her home than the hospital. She spent on autorickshaw expenses. Each time her bandage cost around INR 100 and changed weekly for about 7-8 times.

Women were apprehensive while consulting doctors for their own illness or sick family member. Mani wanted her husband to accompany her to the doctor since she was uncomfortable with hospital set up and was apprehensive of showing the tumour near her breasts. She had to threaten her husband of suicide for a health checkup since he was unwilling to take her to the hospital. There she was sent to an orthopaedic doctor at the ticket counter as she did not have any clue whom to approach. The orthopaedics doctor referred her to a private doctor, wherein she went for consultation, diagnostic test and thereafter, a surgical procedure. She lost time in getting health care for her husband's initial lack of cooperation and incorrect referral at the ticket counter. Women were apprehensive of not only communicating their health issues to the doctor/practitioner, but also of commuting to the health care centre. Sita was only 40 years old, but had no strength to go to the 
hospital when she had leprosy and had barely anything to eat. Kalyani and Bhudei shared how difficult it was to go to the hospital and wait in the que for a health check up with discomfort in body. Both were around 60 years of age and had varying degree of difficulty with their knees and experienced physical weakness due to inadequate meals. Women feared losing earnings on the day of health checkup. Ankamma did not like spending hours at hospitals from paid work and spending money on tests without any major relief in her knee issues.

It was found that women respondents ignored their health issues over family concerns or for such apprehension. The root of ignoring health concerns was class and gender based.

Women shared apprehension about medical expenses such as how will they have enough funds to get the ill family member admitted to the hospital, how would they manage medical expenses of tests, surgery and medication and how would they repay their debt. Expenses were found as a deterrent particularly for surgery or diagnostic test. Amma kept ignoring her tumour to provide for her family of three children after losing her husband and get her daughters married. Later, she did not want to bother her physically handicapped son when surgery was required. Amma did not go for an operation and carried the 6 inch diameter tumour on her back $24^{*} 7$. The swelling increased in its size over the 15 years, an accumulation over the time without intervention. A surgery for its removal would cost her INR 15,000. She also developed acidity, high blood pressure and blood sugar over the years along with tumour. She took medicine every day by spending widow pension money and taking monetary help from her daughters. Mani transitioned from ignoring all her concerns to one who fought with her husband for her health checkup. She sold her land at village and went for a surgery. She overcame the gender and class based constraints while going for her surgery. However, she expressed fears of its recurrence and possible expenses. Continued utilization of health care such as regular medication, checkups and tests over a year was difficult and witnessed discontinuities. Budhi's husband spent his savings of around INR 70,000 on her hospitalization and treatment for brain malaria. Post discharge, she took her blood pressure medicine for one year. After that she stopped taking it as it was expensive.

Each of the cases of brain malaria, pneumonia, gastric ulcer, leg injury and tumour faced delay in health care for reasons of lack of affordability. Very few cases did not incur debt while going for health care. They managed with their savings or by selling off any landed property or pawning gold. When they had taken loans from a money lender, they pushed themselves to work in spite of health issues. Sanju worked to repay a house loan around INR 60,000 and ignored her ulcer symptoms. She did not go for ultrasound test which would cost at least INR 1200 . Anu worked in spite of anaemia and weakness post-delivery. She had a debt for her husband's illnesss which was around INR 30,000. It was usually INR 5 as interest for every INR 100 taken per month till the principal was repaid back. There was no mechanism to give loans to women at minimal rate except some defunct self-help groups. These were closed down due to some financial issues. Physical and psycho-social exposures were found interweaved in debt situation.

\section{Conclusion}

Health issues were found pushing them into shifting to other work or withdrawing from employment. Physical and mental health issues of women workers were interweaved and consequences of interactive exposures situated in work, family, diet and living conditions and challenges of accessing health care. These exposure conditions emerged from gender, class and age intersectionality and multiplied when she was vulnerable. Signifying her state of vulnerability, along with gender, class and age, state support in form of schemes and family's physical as well as financial support intersected to influence further improvement or deterioration of women worker's health. Psycho-social exposures were never attended to and in course of time, accumulated and interacted with physical health. By their mid-40s, both women domestic and construction workers' bodies started showing symptoms of chronic health issues, be it constant cold, knee ache, acidity, weakness of body which worsened with advanced age and recurring exposure conditions. Once any type of health issue surfaced and required urgent medical attention, women experienced illness with challenges of accessing health care as manifested in delays and discontinuities. Lack of policies holding employers accountable for injuries and reimbursement of lost wages for minimum 
duration or lack of access to pension and ration schemes and challenges of health care added to the web of interaction within different exposures of work, family, diet and living conditions. Accumulation and interaction of exposures is critical in understanding how ailments became impeding and multiple in nature without time for recovery, demands of unpaid and paid work, difficulties in accessing health care and lack of access to state schemes. Sen and Ostlin (2007) in their SDH model consider various axes of social stratification, the associated norms, values, exposures and vulnerabilities, the health systems, research biases, interactions and health consequences, but do not take into account the accumulation of risk over the life course. Krieger (2003) mentioned cumulative economic deprivation. The process of deprivation occurred over time and was based on economic, political and social factors. SDH model's structural causes, interactive social, economic and political environment and processes of health exposures and vulnerabilities was inadequate in understanding health of women workers since it did not take into accumulation of health risks along with interactive process. Life course approach's 'accumulation of risk model' along with SDH model was found helpful in explaining this gap in understanding ${ }^{3}$. Health issues found responsible for work changes were broadly of four types based on its nature, viz., injuries, chronic diseases, acute illness and mental health issues. In case of injury or acute illness or mental health issues, health problems immediately hindered paid work. Chronic health problems hindered paid work intermittently since the women lived with the diseases and worked. Health issues affected their paid work in advance of at least 5-8 years than 58 years, a minimum norm age for retirement. India does not have a retirement age policy for construction and domestic workers. In some cases, this happened almost 10-12 years before than the retirement age norm. This implied loss of earnings with no savings and vulnerability to debt and further, health exposures. Early onset of reduced or loss of earnings due to health issues for women workers was preventable, if these conditions and their structural causes were addressed to. The difference between domestic and construction workers was more in terms of nature of illness, with injuries at construction sites also being an intermediate in the pathway of work changes. Rest health issues were the same. For both, family support made a difference in their vulnerability as did state support. Hunger and weakness was more imminent in absence of state support in form of ration supply than absence of family support. This was more so as family earnings were hardly enough. The vulnerabilities involved were complex as exposure conditions occurred on a daily and episodic basis, with interlinked material, physical and psychosocial pathways. The accumulated and interactive complex of multilevel factors and processes appears to be critical if the links of health and women's economic activity are to be understood.

\section{Acknowledgements}

I thank my supervisor Prof. Ritupriya Mehrotra at Centre for Social Medicine and Community Health, Jawaharlal Nehru University for her critical comments and suggestions which helped me immensely while working on this paper. I am grateful to each of the 33 women respondents for their time and voluntary participation in this study.

\section{References}

CSDH. (2008). Closing the gap in a generation: health equity through action on the social determinants of health. Final Report of the Commission on Social Determinants of Health. Geneva: WHO. [Online] Available: http://apps.who.int/iris/bitstream/10665/43943/1/9789241563703_eng.pdf

CSDH. (2007). A Conceptual Framework for Action on the Social Determinants of Health. Discussion paper for the Commission on Social Determinants of Health, DRAFT Last Version. Geneva: WHO. [Online] Available: http://www.who.int/social_determinants/resources/csdh_framework_action_05_07.pdf (April, 2007)

${ }^{3} \mathrm{CSDH}$ (2007:14) refers to the "accumulation of risk" model as indicative of factors that raise disease risk or promote good health may accumulate gradually over the life course, although there may be developmental periods when their effects have greater impact on later health than factors operating at other times. 
Doyal, L. (2000). Gender equity in health: debates and dilemmas. Social Science \& Medicine (1982), 51(6), 931-9.

Doyal, L. (1995). What Makes Women Sick: Gender and the Political Economy of Health. New Jersey: Rutgers University Press.

Graham, H. (2004). Social Determinants and Their Unequal Distribution: Clarifying Policy Understandings. The Milbank Quarterly, 82(1), 101-24.

Hankivsky, O. (2012). Women's Health, Men's Health, and Gender and Health : Implications of Intersectionality. Social Science \& Medicine, 74(11), 1712-20. [Online] Available: http://doi.org/10.1016/j.socscimed.2011.11.029 (June, 2012)

Krieger, N. (2003). Genders, sexes and health: what are the connections-why does it matter? International Journal of Epidemiology, 32 (4) 652-57.

Krieger, N., Alegría, M., Almeida-filho, N., Barbosa, J., Barreto, M. L., Beckfield, J., \& James, S. A. (2010). Who, and what, causes health inequities? Reflections on emerging debates from an exploratory Latin American/ North American workshop. Journal of Epidemiology and Community Health, 64(9), 747-49.

Labonte, R. Schrecker, T. (2007). Towards Health-Equitable Globalisation: Rights, Regulation and Redistribution. Final Report to the Commission on Social Determinants of Health. Ottawa: Institute of Population Health. [Online] Available: http://www.who.int/social_determinants/resources Igkn_report_06_2007.pdf (June, 2007)

Marmot, M., Friel, S., Bell, R., Houweling, T. a J., \& Taylor, S. (2008). Closing the gap in a generation: health equity through action on the social determinants of health. Lancet, 372(9650), 1661-1669 [Online] Available: http://doi.org/10.1016/S0140-6736(08)61690-6 (November, 2008)

McGibbon, E., Francis, S., \& McPherson, C. (2010). Applying Intersectionality \& Complexity Theory to Address the Social Determinants of Women's Health. Nova Scotia: St. Francis Xavier University, 59-86.

Population Council. (2007). The World Health Organization on Health Inequality, Inequity and Social Determinants of Health. Population and Development Review, 33(4), 839-43.

Sen, G., \& Ostlin, P. (2007). Unequal, Unfair, Ineffective and Inefficient Gender Inequity in Health: Why it exists and how we can change it. Final Report to the WHO Commission on Social Determinants of Health. Bangalore \& Stockholm: Indian Institute of Management \& Karolinska Institutet. [Online] Available: http://www.who.int/social_determinants/resources/csdh_media/wgekn_final_report_07.pdf (September, 2007) 